High-speed flow visualization in a pump-turbine under off-design operating conditions

This article has been downloaded from IOPscience. Please scroll down to see the full text article.

2010 IOP Conf. Ser.: Earth Environ. Sci. 12012059

(http://iopscience.iop.org/1755-1315/12/1/012059)

View the table of contents for this issue, or go to the journal homepage for more

Download details:

IP Address: 128.178.4.58

The article was downloaded on 29/11/2010 at 13:33

Please note that terms and conditions apply. 


\title{
High-speed flow visualization in a pump-turbine under off-design operating conditions
}

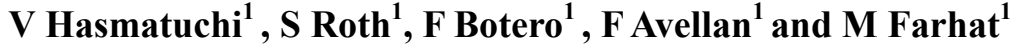 \\ ${ }^{1}$ Laboratory for Hydraulic Machines, École Polytechnique Fédérale de Lausanne \\ Av. de Cour 33bis, Lausanne, CH-1007, Switzerland \\ E-mail: vlad.hasmatuchi@epfl.ch
}

\begin{abstract}
The flow hydrodynamics in a low specific speed radial pump-turbine reduced scale model is experimentally investigated under off-design operating conditions in generating mode. Wall pressure measurements, in the stator, synchronized with high-speed flow visualizations in the vaneless space between the impeller and the guide vanes using air bubbles injection are performed. When starting from the best efficiency point and increasing the runner speed, a significant increase of the pressure fluctuations is observed mainly in channels between wicket gates. The spectral analysis shows a rise of one stall cell, rotating with about $70 \%$ of the impeller frequency, at runaway, which further increases as the zero discharge condition is approached. Then a specific image processing technique is detailed and applied to create a synthetic instantaneous view of the flow pattern on the entire guide vanes circumference for an operating point in turbine-brake mode, where backflow and vortices accompany the stall passage.
\end{abstract}

\section{Introduction}

Pumped storage power plants are playing a growing role in nowadays liberalized electricity market. They offer a great potential of energy storage to cope with the random character of renewable sources such as wind and solar power plants. Reversible pump-turbines also provide an efficient way to stabilize the electricity grid by moving water forth and back between upstream and downstream reservoirs to match both the energy supply and demand. Therefore, modern pump-turbines are subjected to frequent switching between pumping and generating modes with extended operation under off-design conditions. Depending on the specific speed of the pump-turbine, the discharge-speed as well as torque-speed characteristics at constant guide vane opening can be "S-shaped". In this case, the machine operation may become strongly unstable at runaway speed and beyond with a significant increase of structural vibrations and noise.

So far, the issue of pump-turbines operation under off-design conditions in generating mode was poorly addressed in the literature. The flow instabilities, which may develop in a pump-turbine during a sudden load rejection, were addressed by few authors (Pejovic et al. [1], Tanaka and Tsunoda [2], Oishi and Yokoyama [3]). Martin [4], [5] proposed a stability analysis to predict the occurrence of large flow oscillations in idealized machine. $\mathrm{He}$ argued that the unstable operation is mainly due to the presence of a positive slope on the $\mathrm{T}_{\mathrm{ED}}-\mathrm{n}_{\mathrm{ED}}$ characteristic curve regardless of $\mathrm{Q}_{\mathrm{ED}}-\mathrm{n}_{\mathrm{ED}}$ characteristic shape. Nicolet [6] stated that high head pump-turbines, which are commonly of low specific speeds, are more subjected to "S-shaped" characteristic curves. Dörfler et al. [7] proposed an interesting method to avoid unstable operation of pump-turbines during model tests: The inlet valve is partially open and by-passed with a second valve to adjust the flow rate. The resulting artificial head loss improves significantly the hydraulic stability. This procedure is widely used to allow for the exploration of the entire S-shaped characteristic. Kuwabara et al. [8] developed an intelligent governor which was provided with an anti-Scharacteristics control to be used upon load rejection. Billdal and Wedmark [9] introduced the concept of Multiflow Guide Vanes (MGV) to mitigate the flow instabilities. It consists in operating several guide vanes independently from the rest of the guide vane mechanism in order to stabilize the machine.

In the present work, firstly the case study and the experimental setup are presented. Then the analysis of pressure measurements coupled with flow visualizations is used to identify and describe the onset and the development of flow instabilities, starting from the best efficiency point and increasing the impeller speed until the runaway and turbine brake mode are reached. 
Afterwards a specific image processing technique is detailed and applied to create a synthetic instantaneous view of the flow pattern on the entire guide vanes circumference using the acquired high-speed visualizations and finally the main conclusions are drawn.

\section{Experimental setup}

The case study is a model of low specific speed radial pump-turbine, see Fig. 1 (a), installed in the EPFL PF3 test rig. The impeller is made of 9 blades rotating in 20 wicket gates distributor. Off-design conditions, involving runaway and "S-shape" turbine brake curve, are investigated. Starting from nominal operation at fixed guide vane opening, $5^{\circ}$ and $10^{\circ}$, the rotation speed is gradually increased until the runaway is reached. At this point, the operation becomes unstable and the machine may switch forth and back from generating to reverse pumping modes. A specific procedure, commonly used in model testing of pump-turbines, Dörfler [7], is adopted to stabilize the machine operation by forcing the flow through a restriction, bypassing the upstream butterfly valve once the runaway is reached. Wall pressure measurements are performed with piezoresistive pressure sensors flush mounted at the walls of the spiral casing, stay and guide vane channels as well as the draft tube. As represented in Fig. 2, the sensors locations are chosen to cover stator channels from spiral casing up to rotor-stator interface. Both radial and circumferential distributions are included. Pressure signals are simultaneously recorded using VXI HP1432A digitizers with 16 bits A/D resolution, $51200 \mathrm{~Hz}$ sampling frequency and a memory of $1 \mathrm{M}$-samples/channel, providing a maximum of 20 seconds record length. Two air injection holes are drilled on a stator channel upper wall between two stay vanes and two guide vanes. High-speed flow visualizations in the vaneless space between the impeller and the guide vanes were performed through a transparent Plexiglas window with the help of air bubbles injection synchronized with the pressure measurement, see Fig. 1 (b).

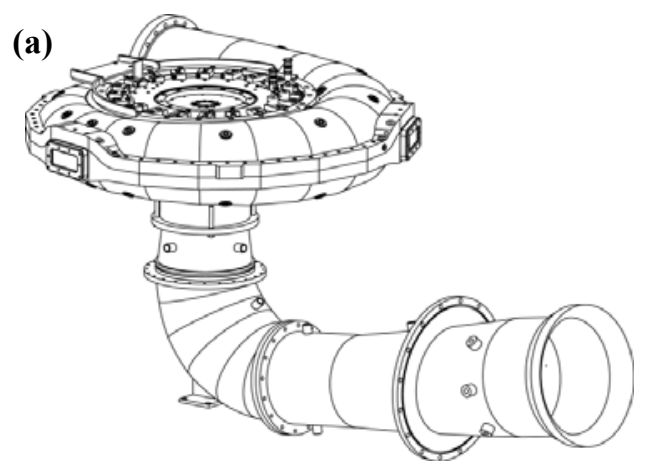

(b)

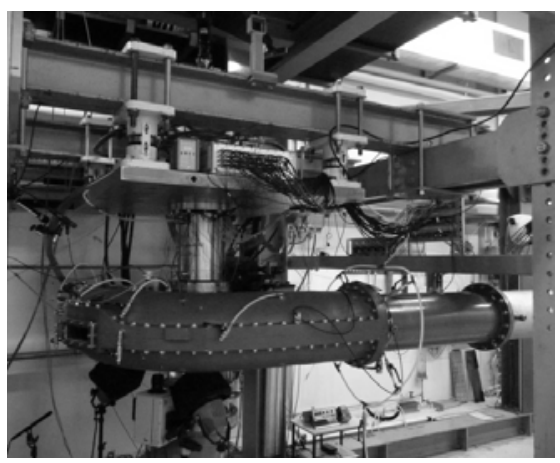

Fig. 1 (a) Hydrodyna reduced model; (b) experimental setup for pressure measurements and high-speed visualization

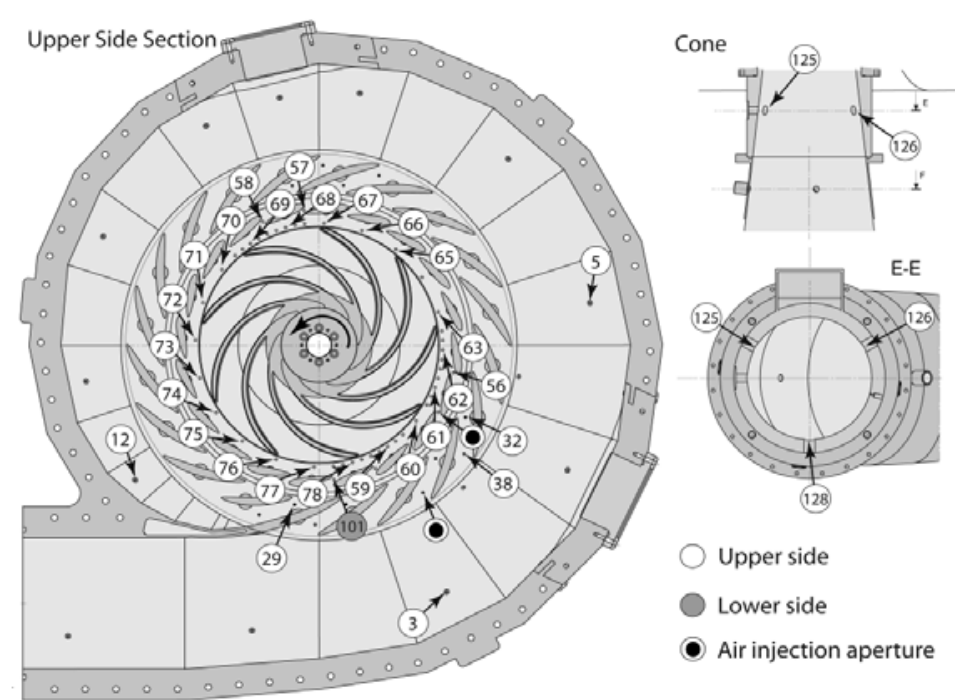

Fig. 2 Pressure sensors location on the model 


\section{Results}

The speed, discharge and torque factors are defined by eq. (1). The runner outlet diameter D is 0.250 [m], while the specific energy E is maintained around $200[\mathrm{~J} / \mathrm{kg}]$ for all operating points. The discharge - speed and torque - speed turbine characteristics (Fig. 3) at $10^{\circ}$ guide vane opening exhibits a positive slope after the runaway speed, OP. \#2. When a pump-turbine prototype is operated in such a condition, the operation suddenly switches to reverse pumping mode. The discharge as well as torque and power are reversed with a substantial increase of structural vibrations driven by flow instabilities. In our case, the use of the stabilizing procedure prevents such unstable operation and let us exploring the positive slope part of the characteristic curve. Once in reverse pumping quadrant, an increase of the rotation speed leads to cavitation development on the impeller blades associated with significant increase of structural vibrations and noise.

$$
n_{E D}=\frac{n D}{\sqrt{E}}, \quad Q_{E D}=\frac{Q}{D^{2} \sqrt{E}}, \quad T_{E D}=\frac{T_{m}}{\rho D^{3} E}
$$
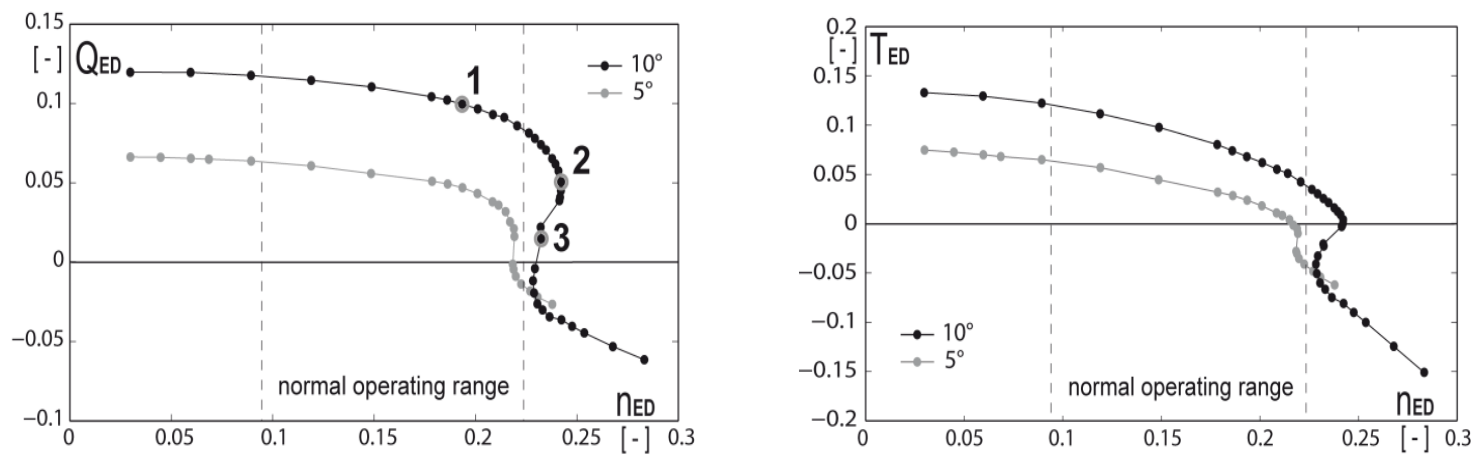

Fig. 3 Resulting "S-shaped" discharge (left) and torque (right) characteristics in generating mode

\subsection{Pressure fluctuations}

A global view of the flow unsteadiness at $5^{\circ}$ and $10^{\circ}$ guide vane openings is obtained by superposing on the $\mathrm{Q}_{\mathrm{ED}}-\mathrm{n}_{\mathrm{ED}}$ characteristic curves, the standard deviation of the pressure fluctuations, defined by eq. (2), in the spiral casing and guide vanes (see Fig. 4). The diameter of the circles is proportional to the standard deviation of pressure normalized by the $\rho E$. We can easily observe that the pressure fluctuations in the guide vane channels, close to rotor/stator interface, are by far more important than in the spiral casing. Moreover, for any given location, the pressure fluctuations are increased for low rotation speed, around the "S-shape" and in reverse pumping mode. At these conditions, a substantial increase of the structural vibrations is observed. It should be noticed that in the particular case of guide vanes, the maximum pressure fluctuation is at least 25 times larger than in nominal conditions and about $15 \%$ of the specific energy. The present analysis let us believe that the source of flow unsteadiness at off-design conditions is likely located in the impeller or in the vaneless space between the impeller and the guide vanes.

$$
\tilde{c}_{p}^{\prime}=\frac{1}{\rho E} \sqrt{\frac{1}{N} \sum_{i=1}^{N}\left(p_{i}-\bar{p}\right)^{2}}
$$
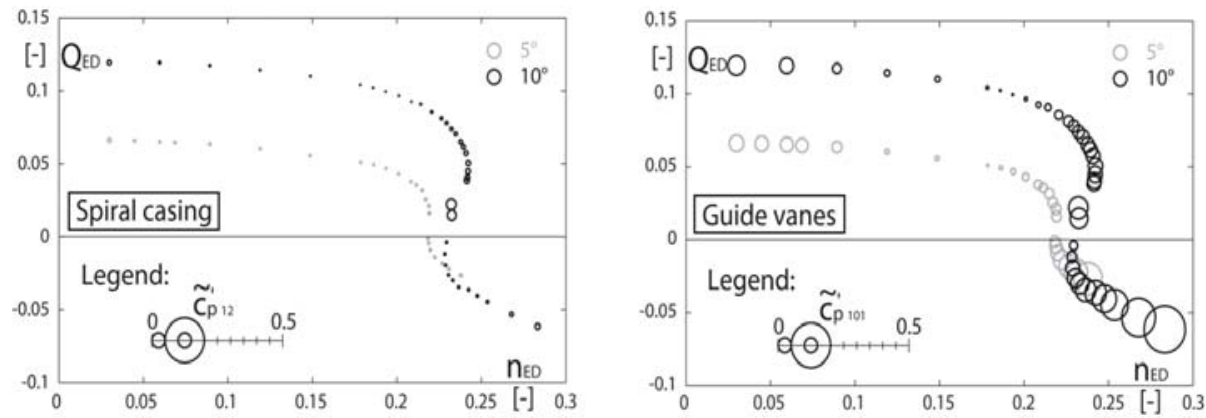

Fig. 4 Pressure fluctuations standard deviation (STD) in spiral casing (left) and guide vanes (right) 
Further analysis is carried out for three operating conditions at $10^{\circ}$ guide vanes opening (see Fig. 3 and Table 1) representing normal operating range (OP. \#1), runaway speed (OP. \#2) and very low positive discharge (OP. \#3).

Table 1 Selected operating points for analysis

\begin{tabular}{c|c|c|c|c}
\hline \hline OP. & $\mathbf{n}_{\text {ED }}$ & $\mathbf{Q}_{\text {ED }}$ & $\mathbf{T}_{\text {ED }}$ & Operation regime \\
\hline$\# \mathbf{1}$ & 0.19335 & 0.09949 & 0.06797 & Best efficiency \\
\hline$\# \mathbf{2}$ & 0.24209 & 0.04493 & 0.00033 & Runaway \\
\hline$\# 3$ & 0.23244 & 0.01483 & -0.02262 & Low discharge \\
\hline
\end{tabular}

The pressure coefficient fluctuation is computed in accordance with eq. (3). Averaged spectra of pressure fluctuations in the spiral casing (sensor 5) and in the guide vanes region (sensor 101) are presented respectively in Fig. 5 (a) and (b) for previously selected operating points. The spectral analysis in the guide vane channels evidences the blade passing frequency and its first harmonic with lower amplitude, $f=9 \cdot f_{n}$ and $f=18 \cdot f_{n}$, except at low discharge operating point. However, a low frequency component, $\sim 70 \%$ of the impeller rotating frequency, arises at runaway, OP. \#2, which further increases in amplitude as we approach the zero discharge condition, OP. \#3. At this point, the sub-synchronous frequency becomes dominant and modulates the blade passing frequency, see Fig. 6 (a). In the spiral casing, the pressure fluctuation amplitude is significantly lower (almost 10 times) than in the guide vanes region and, as reported by Tanaka [10], the blade passing frequency has a lower amplitude than its first harmonic. The low frequency component is also visible in this region, where it becomes dominant in turbine-brake mode for the same low discharge operating point (OP. \#3). Actually, this low frequency represents the signature of the flow unsteadiness at off-design operating conditions. All these observations confirm that the source of flow unsteadiness is likely located either in the impeller or in the vaneless space between impeller and distributor.

$$
\tilde{c}_{p}=\frac{p-\bar{p}}{\rho E}
$$
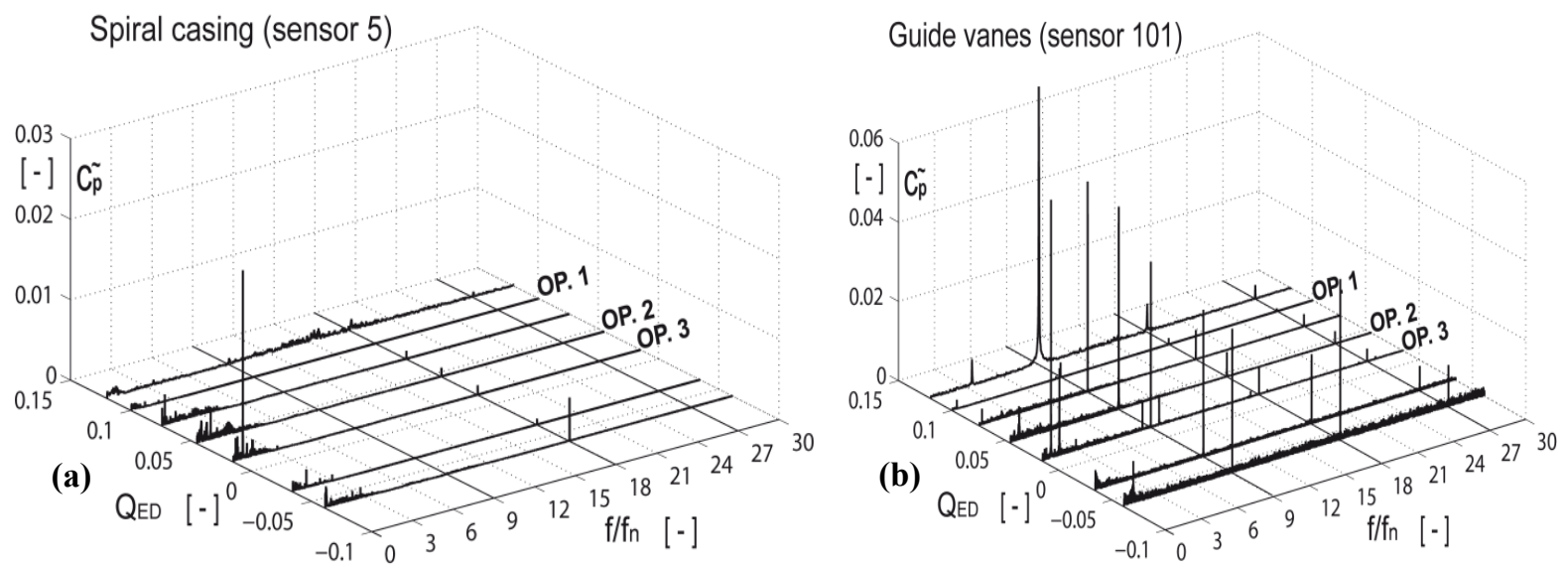

Fig. 5 Averaged pressure fluctuations spectra in: (a) spiral casing; (b) guide vanes

The time history over 10 impeller revolutions corresponding to pressure fluctuation in the vaneless space between the impeller and the guide vanes (sensor 61) are presented in Fig. 6 (a), in comparison between normal operating range (OP. \#1), runaway (OP. \#2) as well as zero discharge condition (OP. \#3). As already observed in the spectra (Fig. 5), the fluctuations amplitude at the normal operating condition is insignificant compared to the zero discharge condition. Surprisingly, the pressure fluctuations at this very unstable operating point are not random but exhibit a remarkable periodicity. We may observe how the rotor-stator interaction frequency is carried by the low frequency component $\left(0.7 \cdot \mathrm{f}_{\mathrm{n}}\right)$. An instantaneous image of the time-pressure fluctuations on the entire vaneless space circumference is given in Fig. 6 (b), with the help of a time-space-amplitude representation. Accordingly, one high pressure instability source rotating with the impeller at sub-synchronous frequency can be observed. Moreover, the high pressure region covers approximately $50 \%$ of the circumference. Vesely et al. [11] tested a medium head pump-turbine model and found that a rotating stall with a frequency of about $60 \%$ of the impeller speed arises at turbine brake and reverse pumping conditions having only one stall cell. 
(a)

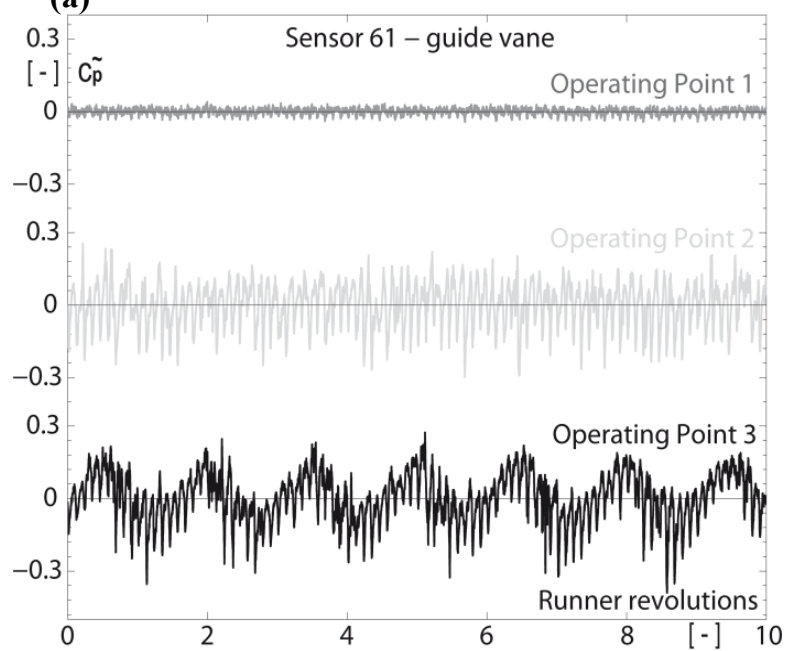

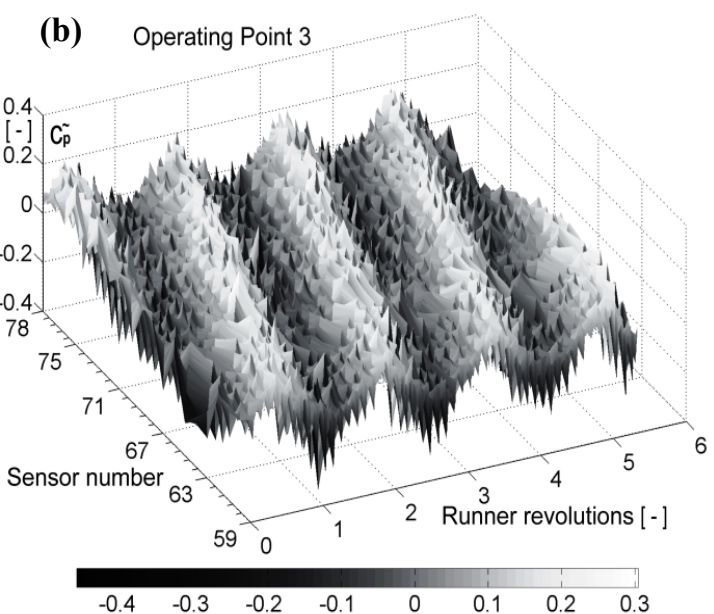

Fig. 6 Pressure-time history in the vaneless space for: (a) the 3 selected operating points;

(b) low discharge operating point (OP. \#3) over the entire vaneless circumference

\subsection{Flow visualization}

In order to describe the hydrodynamics of the flow instability, high-speed visualizations were accomplished with the help of air bubbles injection in the vaneless space between the impeller and the guide vanes. The volume of gas was regulated with the help of a valve, whereas the pressure was set constant slightly above the mean pressure level at the injection location. Instantaneous captures of the flow pattern in the guide vanes region for the normal operating range (OP. \#1), runaway (OP. \#2) and very low positive discharge (OP. \#3) conditions are illustrated in Fig. 7. Once released, the air bubbles travel along the streamlines specific to each operating point. We can observe a quite continuous and uniform flow for the normal operating range, but at runaway the flow pattern is disturbed by the presence of vortices traveling in the vaneless space. The perturbation is more pronounced for low discharge condition, where backflow and vortices are observed in the guide vanes channel.

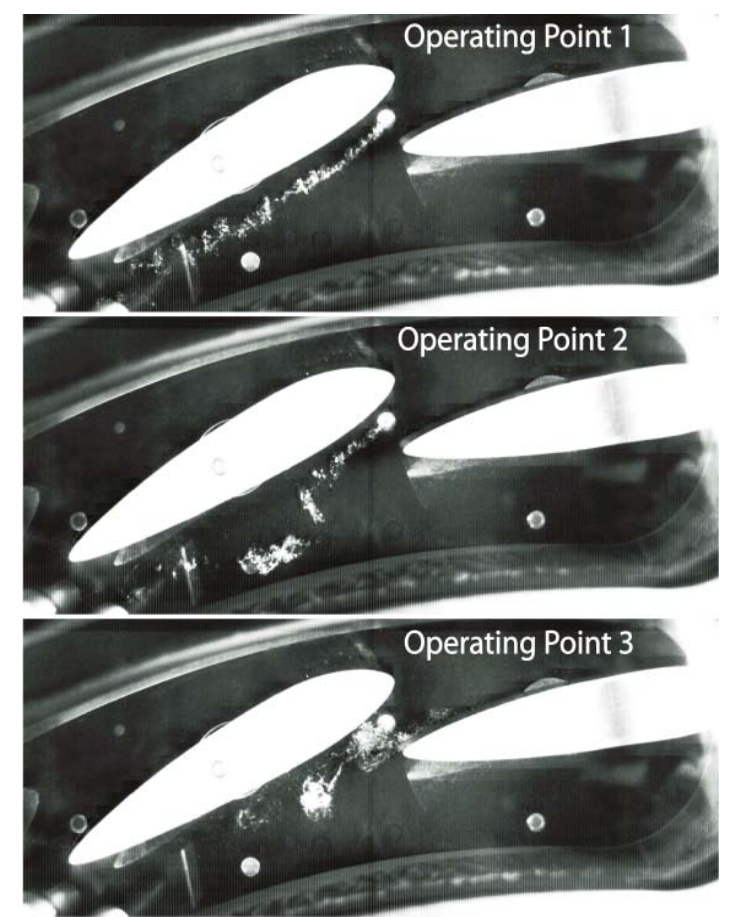

Fig. 7 Flow visualization with the help of air bubbles injection in a guide vanes channel 


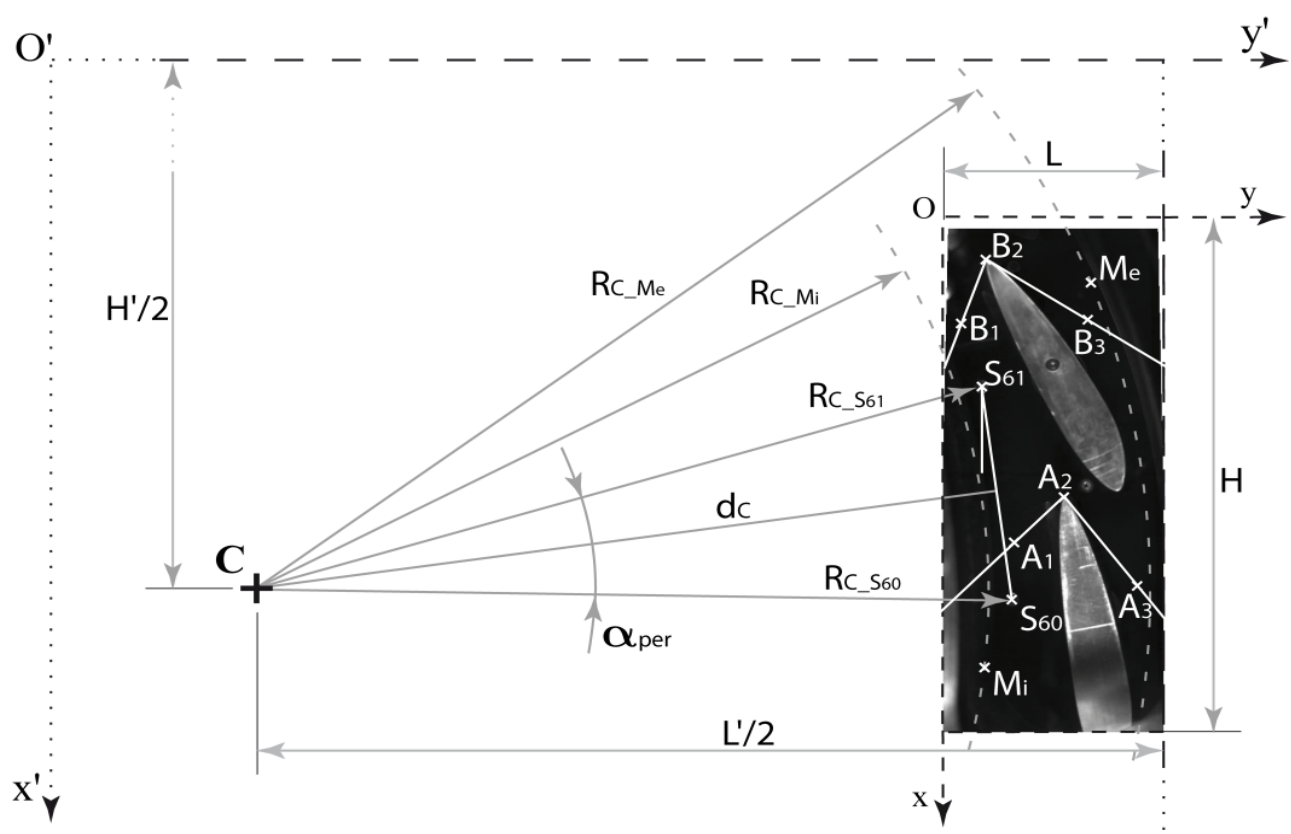

Fig. 8 Schematic of image processing operations for creating the synthetic flow visualization over the entire guide vanes circumference

\subsection{Image processing}

A specific image processing is performed on high speed movies at low discharge operating point (OP. \#3). As stated above for this case, one stall cell rotates periodically in the vaneless space with the impeller at subsynchronous speed. Therefore, a time distribution of the phenomenon can be represented as a space distribution by placing images for one period of the rotating stall, with appropriate phase shift to obtain instantaneous views of the flow pattern in the entire distributor. In Fig. 8, the schematic representation of image processing operations for creating the synthetic flow visualization over the entire guide vanes circumference is illustrated. The programming is performed within MATLAB environment. The image processing procedure may be described as follows: Firstly, the high-speed flow visualization movie for OP. \#3 is imported as pictures frameby-frame in a $3 \mathrm{D}$ vector. Then, the images perspective is corrected with an angle of $15^{\circ}$. The air bubbles are injected through the aperture placed in the guide vanes channel (see the aperture position in Fig. 2). The coordinates of the pressure sensors 60 and 61 are recovered from images in pixel units, in the Oxy coordinates system (see Fig. 8). The rotation center, $\mathrm{C}$, in pixel coordinates, is then computed knowing the $18^{\circ}$ angle between 2 wicket gates. A mask is used in order to extract from images only one guide vane and the corresponding adjacent channel containing the air injection aperture. The coordinates in pixel units of $A_{1}, A_{2}$ and $A_{3}$ points are recovered from the images. Then, their periodic correspondent points, respectively $B_{1}, B_{2}$ and $B_{3}$, are calculated. The slopes of the $A_{1} A_{2}$ and $A_{2} A_{3}$ respectively $B_{1} B_{2}$ and $B_{2} B_{3}$ lines are computed and used to define the periodic limits of the mask.

A new coordinates system O' $x^{\prime} y$ ' is then defined in accordance with the new global image sizes, H' and L'. The rotation center of the machine, $\mathrm{C}$, is placed in the center of the new created global image. Finally, 20 processed images are extracted from one rotating stall period and placed on the final global figure to cover the entire guide vanes. A radial mask is applied to cut the interior and exterior sides of the guide vanes circumference. Repeating the procedure for each movie time step, a high-speed visualization of the entire vaneless space circumference is provided. The result for one time step is illustrated in Fig. 9. The impeller is placed in the center of the figure at its real position. A contour plot of the low-pass filtered pressure fluctuation (the rotor-stator interaction fluctuations were filtered) for the sensor 61, placed in the vaneless space downstream the air injection aperture, is represented between the guide vanes and the impeller for one rotating stall period. The rotor-stator interaction pressure component cannot be appropriately represented in space since its frequency is not a multiple of the rotating stall frequency. The pressure contour is in accordance with the flow visualization for each angular position. The injected air bubbles are visible only on a half of the circumference when the air pressure exceeds the pressure inside the flow. 


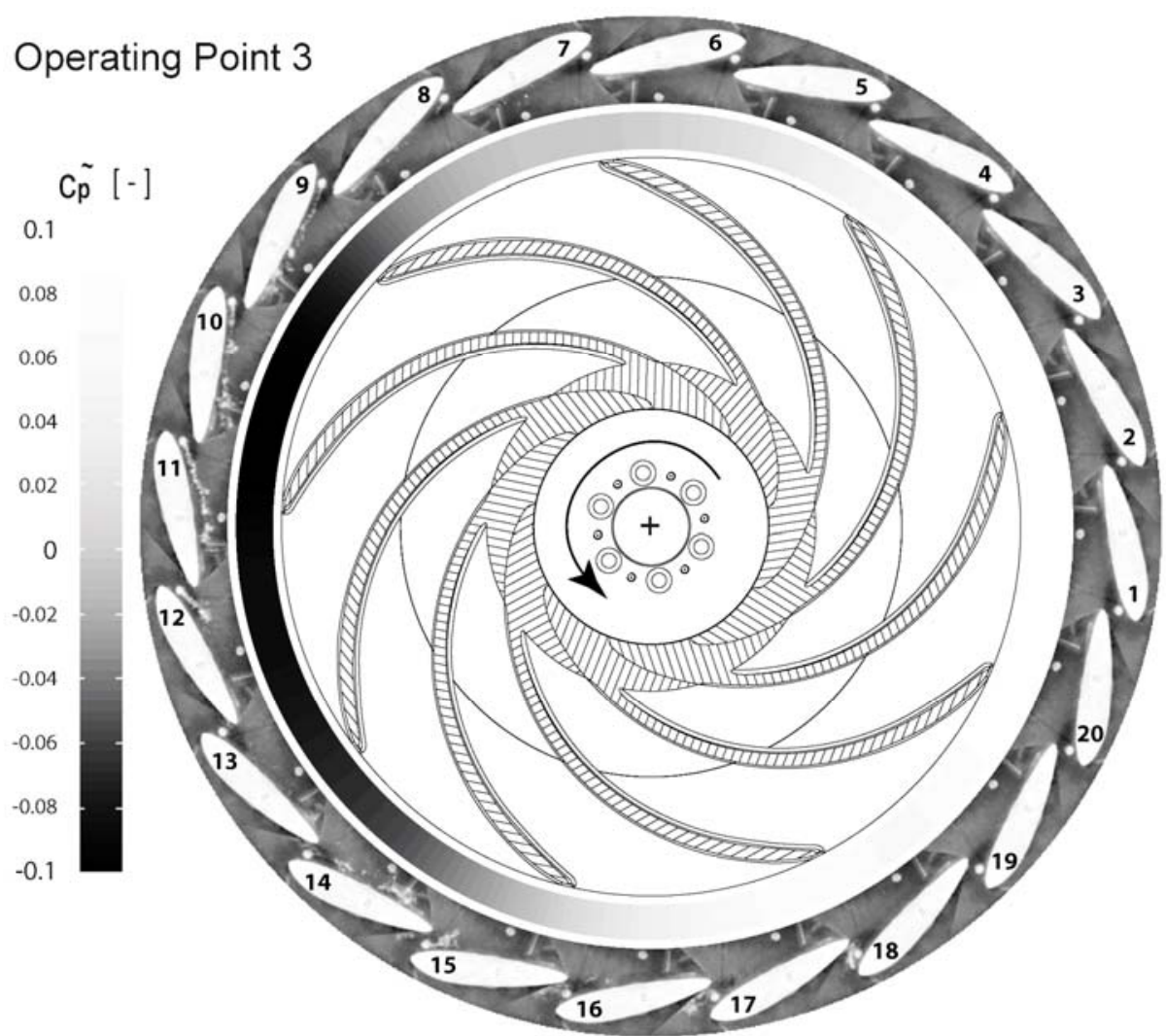

Fig. 9 Instantaneous synthetic flow visualization in the entire guide vanes circumference

This is in accordance with the pressure fluctuation contour, where no bubbles are visible in the channels between the guide vanes 6 to 18. Channels between the guide vanes 18 to 14 present the state of the flow at the end of the stall passage. Vortices and backflows dominate the flow pattern. Once the rotating stall is passed, channels between guide vanes 14 to 6 , the flow returns step by step to a uniform pattern. In the channels between the guide vanes 9 to 6 , the flow is even similar with the one in the normal operating range (see Fig. 7 - OP. \#1).

\section{Conclusions}

The present work is focused on the experimental investigation of the hydrodynamic in a low specific speed radial pump-turbine model under off-design operating conditions in generating mode. Wall pressure measurements, in the stator, synchronized with high-speed flow visualizations in the vaneless space between the impeller and the guide vanes using air bubbles injection are performed. The detailed analysis of pressure measurements reveals a rise of a low frequency component of about $70 \%$ of the impeller rotational frequency, at runaway, which further increases in amplitude as the zero discharge condition is approached. The time-pressure distribution in the vaneless space between the impeller and guide vanes shows one stall cell rotating with the impeller at sub-synchronous speed. High-speed visualization illustrates a quite uniform flow pattern in the guide vane channels at the normal operating range, whereas at runaway the flow is highly disturbed by the rotating stall passage. The situation is even more critical near zero discharge, where backflow and vortices in the guide vane channels accompany the stall passage. A specific image processing is detailed and applied to create a synthetic instantaneous view of the flow pattern on the entire guide vanes circumference, for the low positive discharge operating point, using the acquired high-speed visualizations.

To sum up, the flow in a pump-turbine operating under off-design conditions in generating mode, in the Sregion, is dominated by one stall cell rotating with the impeller at sub-synchronous speed in the vaneless space between the impeller and guide vanes. It is likely the result of flow separations developed in several consecutive impeller channels, which lead to their blockage. Obviously, this rotating hydrodynamic instability is responsible of hydraulic unbalance and strong structural vibrations. 


\section{Acknowledgments}

The present investigation was carried out in the frame of HYDRODYNA II project (Eureka $\mathrm{N}^{\circ} 4150$ ), in a partnership with ALSTOM Hydro, ANDRITZ Hydro, VOITH Hydro and UPC-CDIF. The authors would like to thank the Swiss Federal Commission for the Technology and Innovation (CTI), Swisselectric Research and Swiss Competence Center of Energy and Mobility (CCEM) for their financial support as well the HYDRODYNA II partners for their involvement and support.

\section{Nomenclature}

$\begin{array}{llll}\alpha_{p e r} & \text { Periodicity angle }\left[{ }^{\circ}\right] & x, y & \text { Cartesian coordinates [pixel] } \\ \rho & \text { Water density }\left[\mathrm{kg} / \mathrm{m}^{3}\right] & D & \text { Impeller outlet diameter }[\mathrm{m}] \\ \tilde{c}_{p} & \text { Pressure coefficient [-] } & E & \text { Specific energy [J/kg] } \\ \tilde{c}_{p} & \text { Pressure fluctuation standard deviation [-] } & H, L & \text { Image height and respectively length } \\ d & \text { Distance between two points [pixel] } & N & \text { Samples number [-] } \\ f & \text { Frequency [Hz] } & Q & \text { Discharge }\left[\mathrm{m}^{3} / \mathrm{s}\right] \\ f_{n} & \text { Impeller frequency [Hz] } & R & \text { Circle radius [pixel] } \\ n & \text { Impeller speed [1/s] } & Q_{E D} & \text { Discharge factor [-] } \\ n_{E D} & \text { Speed factor [-] } & T_{E D} & \text { Torque factor [-] } \\ p & \text { Wall pressure [Pa] } & T_{m} & \text { Impeller torque }[\mathrm{Nm}] \\ \bar{p} & \text { Time average wall pressure }[\mathrm{Pa}] & & \end{array}$

\section{References}

[1] Pejovic S, Krsmanovic L, Jemcov R. and Crnkovic P 1976 Unstable Operation of High-Head Reversible Pump-Turbines Proc. of $8^{\text {th }}$ IAHR Symp. on Hydr. Mach. and Cavitation pp 283-295 (Leningrad, Russia)

[2] Tanaka H and Tsunoda S 1980 The Development of High Head Single Stage Pump-Turbines Proc. of $10^{\text {th }}$ IAHR Symp. on Hydr. Mach. and Cavitation pp 429-440 (Tokyo, Japan)

[3] Oishi A and Yokoyama T 1980 Development of High-Head Single- and Double-Stage Reversible PumpTurbines Proc. of $10^{\text {th }}$ IAHR Symp. on Hydr. Mach. and Cavitation pp 441-452 (Tokyo, Japan)

[4] Martin C S 1986 Stability of Pump-Turbines during Transient Operation The $5^{\text {th }}$ Int. Conf. on Pressure Surges (Hannover, Germany)

[5] Martin C S 2000 Instability of Pump-Turbines with S-Shaped Characteristics Proc. of 20 th IAHR Symp.Hydr. Mach. and Syst. (Charlotte, USA)

[6] Nicolet C 2007 Hydroacoustic Modeling and Numerical Simulation of Unsteady Operation of Hydroelectric Syst. PhD thesis No. 3751 EPFL (Lausanne, Switzerland)

[7] Dörfler P K, Engineer A J, Pendse R N, Huvet P and Brahme M V 1998 Stable Operation Achieved on a Single-Stage Reversible Pump-Turbine Showing Instability at No-load Proc. of $19^{\text {th }}$ IAHR Symp. Hydr.Mach. and Syst. (Singapore)

[8] Kuwabara T, Katayama K, Nakagawa H and Hagiwara H 2000 Improvements of Transient Performance of Pump Turbine upon Load Rejection Power Eng. Society Summer Meeting (Seattle, WA, USA) vol 3 pp 1783-88

[9] Billdal J T and Wedmark A 2007 Recent Experiences with Single-Stage Reversible Pump Turbines in GE Energy's Hydro Business Hydro 2007 (Granada, Spain) p 10.3

[10] Tanaka H 1990 Vibration Behavior and Dynamic Stress of Runners of Very High Head Reversible PumpTurbines The $15^{\text {th }}$ IAHR Symp. on Hydr. Mach. and Cavitation (Belgrade, Yugoslavia)

[11] Vesely J, Pulpitel L and Troubil P 2006 Model Research of Rotating Stall on Pump-Turbines Hydro 2006 (Porto Carras, Greece) p 3.5

[12] Staubli T, Senn F and Sallaberger M 2008 Instability of Pump-Turbines During Start-up in the Turbine Mode Hydro 2008 (Ljubljana, Slovenia) p 9.6 